Hikmah: Journal of Islamic Studies, 17 (2), 2021, 148-159

http://journal.uinjkt.ac.id/index.php/HIKMAH

DOI: 10.47466/hikmah.v17i2.202. | P-ISSN. 2088-2629, E-ISSN. 2581-0146

\title{
EFEK GLOBALISASI DALAM PERSPEKTIF PENDIDIKAN
}

\author{
Ade Zaenudin ${ }^{1}$, Yazid Hady ${ }^{2 *}$ \\ ${ }^{1}$ MTs Negeri 3 Kota Tangerang, Indonesia \\ ${ }^{2}$ UIN Syarif Hidayatullah Jakarta, Indonesia \\ yazidhady@uinjkt.ac.id
}

\begin{abstract}
Globalization can be interpreted as a condition where human interaction is not separated by space and time. In this condition, the competition for life is getting tougher because it does not only intersect with the local community but with the global community. This study focuses on analyzing the effects of globalization on education programs in Indonesia. This study uses qualitative research methods with literature studies. Based on the results of literature research, globalization has implications for the face of the world of education, start shifting from tradition to modernization, from social spiritual to commercial, and from local to universal. The researcher also identified the presence of eight programs as an effect of globalization in the world of education, the inclusion of foreign languages as learning materials, the presence of foreign language/literature majors, program collaboration between cross-country educational institutions, collaboration with foreign donor agencies, the existence of an international level Student Competency Assessment, establishment of cross-border educational institutions, cross-country lecturer exchanges, and student exchanges between countries.
\end{abstract}

Keywords: globalization; education; globalization of education

Abstrak
Globalisasi bisa dimaknai sebagai sebuah keadaan dimana interaksi manusia sudah tidak bersekatkan ruang dan waktu. Dalam kondisi ini, persaingan hidup semakin ketat karena tidak hanya bersinggungan dengan komunitas lokal saja tapi jauh lebih luas yaitu dengan komunitas global. Penelitian ini fokus menganalisis bagaimana efek globalisasi terhadap program Pendidikan di Indonesia. Penelitian ini menggunakan metode penelitian kualitatif dengan studi literatur. Berdasarkan hasil penelitian literatur ditemukan fakta bahwa globalisasi berimplikasi pada wajah dunia pendidikan mulai dari pergeseran tradisi ke modernisasi, sosial spiritual ke komersial, dan dari lokal ke universal. Peneliti juga mengidentifikasi hadirnya delapan program sebagai efek globalisasi di dunia pendidikan, yaitu masuknya bahasa asing sebagai materi pembelajaran, hadirnya jurusan bahasa / sastra asing, kerjasama program antar lembaga pendidikan lintas negara, kerjasama dengan lembaga donor luar negeri, adanya Asesmen Kompetensi Siswa tingkat internasional, pendirian lembaga pendidikan lintas negara, pertukaran dosen lintas negara, dan adanya pertukaran pelajar antar negara.

Kata Kunci: globalisasi; pendidikan; globalisasi pendidikan 


\section{PENDAHULUAN}

Globalisasi adalah suatu proses menjadikan sesuatu (benda atau perilaku) sebagai ciri dari setiap individu di dunia tanpa dibatasi oleh wilayah ". Globalisasi diambil dari kata globalize yang merujuk pada kemunculan jaringan sistem sosial dan ekonomi berskala internasional. Seorang ahli ekonomi bernama Theodore Levitt mengenalkan kata globalisasi pada tahun 1985 melalui artikelnya yang berjudul "Globalization of Markets" yang diterbitkan Harvard Business Review. Jika diartikan secara sederhana, globalisasi merupakan proses integrasi internasional yang terjadi karena adanya pertukaran pandangan dunia, produk, pemikiran, dan aspek kebudayaan lainnya di dunia.

Apollo dalam artikelnya di Kompasiana.com mengatakan bahwa globalisasi meliputi aspek ekonomi, budaya, sosial, ekologi dan teknologi. Menurutnya globalisasi adalah pemadatan ruang dan waktu (globus), sebuah proses sejarah di mana jaringan dan sistem hubungan sosial berkembang secara spasial dengan perilaku, aktivitas, dan pelaksanaan kekuasaan sosial manusia mengambil karakter lintas benua (atau antar wilayah). Roland Robertson, dosen sosiologi Universitas Aberdeen, salah satu penulis pertama di bidang globalisasi, mendefinisikan globalisasi sebagai pemadatan dunia dan pemerkayaan kesadaran dunia secara keseluruhan ${ }^{2}$. Sementara sosiolog Martin Albrow dan Elizabeth King mendefinisikan globalisasi sebagai semua proses yang menyatukan penduduk dunia menjadi satu masyarakat dunia yang tunggal ${ }^{3}$. Anthony Giddens dalam The Consequences of Modernity, memaknai globalisasi sebagai intensifikasi hubungan sosial dunia yang menghubungkan tempat-tempat jauh sehingga peristiwa di suatu tempat dapat dipengaruhi oleh peristiwa yang terjadi di tempat lain sekian kilometer jauhnya dan sebaliknya ${ }^{4}$. Jan Aart Scholte menyebut kata globalisasi semakna dengan internasionalisasi, liberalisasi, universalisasi, dan westernisasi ${ }^{5}$.

Ciri globalisasi menurut Jurgen Habermas adalah meningkatnya ketergantungan ekonomi, politik dan jaringan komunikasi global serta semakin besarnya pengaruh perusahaan transnasional. Oleh karenanya, globalisasi mampu meningkatkan cakupan dan intensifikasi lalu lintas, komunikasi dan transportasi hubungan pertukaran lintas batas negara. Bagi Habermas, istilah jaringan merupakan elemen penting dari fenomena globalisasi. Habermas mengistilahkan kondisi globalisasi ini dengan kompetisi internasional 6

\footnotetext{
${ }^{1}$ Achmad Suparman, Ekonomi Lokal Dan Daya Saing Global (Jakarta: Bumi Aksara, 2002).

${ }^{2}$ Roland Robertson, Globalization: Social Theory and Global Culture (London: Sage, 1992).

${ }^{3}$ Elizabeth King (eds.) Martin Albrow, Globalization, Knowledge and Society (London: Sage, 1990), 8.

${ }^{4}$ Anthony Giddens, The Consequences of Modernity (Cambridge: Polity Press, 1991), 64.

${ }^{5}$ Jan Aart Scholte, "Civil Society and Democracy in Global Governance," Global Governance 8 No. 3 (2002):

${ }^{6}$ Stephen J. Ball, Education, Globalisation, and New Times (New York: Routledge Taylor \& Prancis Grou,
} $281-304$ 2007). 
Dari beberapa pendapat tersebut, globalisasi bisa dimaknai sebagai sebuah keadaan dimana interaksi manusia sudah tidak bersekatkan ruang dan waktu. Dalam kondisi ini, persaingan hidup semakin ketat karena tidak hanya bersinggungan dengan komunitas lokal saja tapi jauh lebih luas yaitu dengan komunitas global. Lalu bagaimana efek globalisasi dalam perspektif dunia pendidikan?

\section{METODE}

Penelitian ini fokus menganalisis bagaimana efek globalisasi terhadap program pendidikan, khususnya pada lembaga pendidikan di Indonesia. Penelitian ini menggunakan metode kualitatif. menurut Sugiyono penelitian kualitatif dapat digunakan untuk meneliti permasalahan yang bersifat sementara, dan akan berkembang setelah seorang peneliti sudah mulai terjun ke lapangan untuk melakukan penelitian ${ }^{7}$. Metode penelitian kualitatif merupakan metode penelitian yang sesuai karena penelitian yang akan diteliti merupakan suatu pembahasan yang sewaktu-waktu akan berubah dan berkembang sesuai dengan situasi sosial yang ada.

Pendekatan yang digunakan dalam penelitian ini yaitu studi literatur. Studi literatur merupakan rangkaian kegiatan yang berkenaan dengan metode pengumpulan data pustaka, membaca, dan mencatat, serta mengolah bahan penelitian ${ }^{8}$. Studi literatur bertujuan untuk mengembangkan aspek teoritis maupun aspek manfaat praktis sebagai dasar pijakan untuk memperoleh atau membangun landasan teori, kerangka berpikir serta menentukan hipotesis atau dugaan sementara sehingga peneliti dapat mengelompokkan, mengalokasikan, mengorganisasikan, dan menggunakan variasi pustaka dalam bidangnya ${ }^{9}$

Studi literatur yang dilakukan peneliti dalam hal ini adalah fokus terkait globalisasi dan efeknya terhadap dunia pendidikan di Indonesia. Peneliti berusaha mengorganisasi masalah serta berusaha mengungkap masalah-masalah tersebut dari berbagai referensi, baik itu dari buku, jurnal, berita, baik media online maupun media cetak.

\section{PEMBAHASAN}

Apollo mengatakan bahwa globalisasi bermuara pada lima aspek, yaitu ekonomi, budaya, sosial, ekologi dan teknologi, sementara Manfred Steger mengidentifikasi globalisasi hanya dalam empat dimensi, yaitu ekonomi, politik, budaya, dan ekologi ${ }^{10}$. Kenyataannya hari ini globalisasi ternyata merambah juga pada dunia pendidikan. Ada dua

\footnotetext{
${ }^{7}$ Sugiyono, Metode Penelitian Kuantitatif, Kualitatif, Dan R\&D (Bandung: CV. Alfabeta, 2017).

${ }^{8}$ Mestika Zed, Metode Penelitian Kepustakaan (Jakarta: Yayasan Obor Indonesia, 2008).

${ }^{9}$ H Darmadi, Metode Penelitian Pendidikan (Bandung: CV. Alfabeta, 2011).

${ }^{10}$ Manfred Steger, Globalization: A Very Short Introduction (New York: Oxford University Press, 2009), 11.
} 
asumsi yang bisa dikembangkan, pertama globalisasi mempengaruhi dunia pendidikan, kedua pesatnya dunia pendidikan berimplikasi padi tumbuh kembangnya globalisasi. Apapun asumsi dan argumentasinya, fakta menunjukan bahwa wajah dunia pendidikan saat ini sudah mengalami perubahan besar, hal ini bisa dilihat dari tiga indikator berikut:

\section{Dari Tradisi ke Modernisasi}

Anthony Giddens dalam "The Juggernaut of Modernity" menjelaskan bahwa modernitas layaknya sebuah kendaraan besar yang akan terus melaju menggiring masyarakat untuk terus berlari menuju masa depan dan akan melindas apapun yang tetap berada di tempatnya. Konsekuensinya adalah manusia yang tidak dapat mengimbangi arus perkembangan jaman maka dia akan tertinggal. ${ }^{11}$. Atas dasar hal inilah maka transformasi tradisi menuju modernisasi menjadi sesuatu yang tidak bisa dihindari.

Sebagai sebuah upaya pembangunan masa depan bangsa, modernitas mutlak memerlukan keikutsertaan pendidikan untuk menstimulir dan menyertai setiap proses pembangunan tersebut. Dr. Gooding ${ }^{12}$ mengatakan bahwa setiap fase pembangunan tersebut memerlukan civic consciousness and community responsibility among the people (kesadaran dan tanggung jawab masyarakat secara bersama-sama). Kesadaran dan tanggung jawab masyarakat itu dipengaruhi dan dibingkai oleh aspek pendidikan masyarakatnya itu sendiri. Oleh karenanya, modernisasi tidak bisa terlepas dari pendidikan.

Pendidikan adalah sarana internalisasi nilai luhur dari sosok pendidik kepada peserta didik, dari orang tua ke anak, dari guru ke murid. Kondisi ini tentu sangat melekat dalam sebuah keluarga. Orang tua berkewajiban menyuplai ilmu pengetahuan untuk anaknya agar kelak bisa melanjutkan kehidupan orang tuanya. Dalam beberapa kondisi keterbatasan pengetahuan orang tua, anak diberikan kesempatan untuk menimba ilmu pengetahuan dari orang lain yang dianggap mumpuni dalam ilmu pengetahuan tersebut, muncullah kata "guru" yang awalnya hadir secara non formal lalu dikemudian hari bertransformasi ke wilayah pendidikan formal. Pada saat pendidikan masuk ke wilayah formal inilah kemudian modernisasi lembaga pendidikan tidak bisa dielakkan. Aspek legal formal dari pemerintah tentu berkontribusi terhadap kondisi tersebut sebagai konsekwensi dari peningkatan mutu yang merupakan imbalan atas pendanaan yang semakin mendapat perhatian. Terlebih dana itu bersumber dari dunia internasional.

\footnotetext{
${ }^{11}$ Dwi Kasi Kusumawati Ankarlina Pandu Primadata, "Modernisasi Pendidikan Di Indonesia Sebuah Perspektif Sosiologis Terhadap Dunia Pendidikan Di Indonesia," Jurnal Analisa Sosiologi 3 No.1 (2014): 35.

${ }^{12}$ Nur Dzajifah, Proses Perubahan Sosial Di Masyarakat (Yogyakarta: Lembaga Penelitian dan Pengabdian kepada Masyarakat, 2012), 61.
} 


\section{Dari Sosial Spiritual ke Komersial}

Pendidikan pada dasarnya adalah proses memanusiakan manusia, menjadikan manusia berfikir, bersikap, bertindak dan berucap layaknya manusia, sehingga menjadi pembeda dari makhluk yang lain. Pada kondisi ini, pendidikan dibalut nilai-nilai sosial dan spiritual yang begitu kental. Hal ini diperkuat oleh Undang-undang No. 20 tahun 2003, tepatnya di pasal 1 yang menyatakan bahwa "pendidikan adalah usaha sadar dan terencana untuk mewujudkan suasana belajar dan proses pembelajaran agar peserta didik secara aktif mengembangkan potensi dirinya untuk memiliki kekuatan spiritual keagamaan, pengendalian diri, kepribadian, kecerdasan, akhlak mulia serta keterampilan yang diperlukan dirinya, masyarakat, bangsa, dan negara”. Definisi tersebut memberikan pesan yang kuat bahwa pendidikan berada di ranah sosial spiritual. Akan tetapi globalisasi lambat laun mengajak dunia pendidikan untuk masuk pada ranah komersialisasi sebagai efek dari modernisasi dan globalisasi. Kapitalisasi pendidikan menjadi sesuatu yang tidak terelakkan.

Broon mengatakan bahwa ada empat fungsi pendidikan, yaitu transmisi budaya, meningkatkan integrasi sosial, mengadakan seleksi dan alokasi tenaga kerja, dan mengembangkan kepribadian ${ }^{13}$. Dengan empat fungsi pendidikan tersebut Broon menegaskan bahwa fungsi pendidikan bukan hanya pada pengembangan kepribadian, sosial, dan budaya saja, akan tetapi harus adaptif terhadap dunia kerja. Lembaga pendidikan menjadi tempat mencari penghasilan serta menjadi sarana bagi masyarakat untuk mengantarkan pada masa depan yang berpenghasilan. Kondisi ini kemudian diistilahkan Habermas sebagai industrialisasi pendidikan. Secara filosofis tentu terjadi pergeseran dari pendidikan berbasis humanis menuju kapitalis.

Lebih jauh, Habibie memberikan kritik terhadap praktik pendidikan saat ini, menurutnya komersialisasi pendidikan telah mengantarkan pendidikan sebagai instrument untuk melahirkan buruh-buruh bagi sektor industri, bukan sebagai proses pencerdasan dan pendewasaan masyarakat. Praktik pendidikan layaknya sebagai lembaga penghasil mesin yang siap men-supplay pasar ondustri dan diukur secara ekonomis. Pendidikan menjadi hal yang ekslusif dan jauh dari masyarakat umum bahkan hanya dinikmati kalangan tertentu ${ }^{14}$.

\section{Dari Lokal ke Universal}

Salah satu kekayaan manusia adalah kemajemukan, uniknya kemajemukan yang dimiliki manusia itu tidak dalam satu atau dua aspek saja tapi dalam banyak aspek, baik itu bahasa, suku, ras, golongan dan lain sebagainya. Pendidikan adalah sarana manusia mengenal diri dan lingkungannya agar bisa berinteraksi antar sesama dengan baik. Di lain

\footnotetext{
${ }^{13}$ Jamaluddin Arifin Asmirawanti, Sulfasyah, "Komersialisasi Pendidikan," Equilibrium Pendidikan Sosiologi IV No.2 (2016): 176.

${ }^{14}$ Darmaningtyas, Pendidikan Yang Memiskinkan (Yogyakarta: Galang Press, 2004), 257.
} 
pihak perkembangan ilmu pengetahuan dan teknologi mampu merubah jangkauan pandangan manusia dari lingkup lokal menuju pandangan yang lebih universal. Kondisi seperti ini ternyata bukan hanya dipahami sebagai sebuah hambatan tapi menjadi peluang sekaligus tantangan bagi terciptanya peradaban yang lebih baik. Alfin Toffler bahkan mengumpamakan teknologi sebagai mesin besar atau sebuah eskalator dahsyat dan ilmu pengetahuan adalah bahan bakarnya ${ }^{15}$.

Mahatma Gandhi ternyata punya pandangan yang berbeda, baginya kondisi pergeseran lokal ke universal justru merupakan sesuatu yang mengkhawatirkan. Pendidikan bahasa Inggris ditengarai bisa menggusur bahasa daerah bagi siswa di India, kondisi yang sangat menyedihkan tentunya ${ }^{16}$. Roger Dale menegaskan bahwa sejatinya globalisasi tidak dapat direduksi menjadi pengenaan kebijakan yang sama di semua negara. Namun, meskipun diakui secara luas bahwa globalisasi memang mempengaruhi kebijakan nasional di berbagai bidang ${ }^{17}$.

Arus globalisasi di dunia pendidikan sudah tidak bisa dibendung lagi, lembaga pendidikan justru malah bersaing gengsi menampakan wajah modern sesuai dengan kapabilitas, kompetensi dan perspektif yang dimilikinya. Wajah globalisasi pendidikan pun kian beragam. Mari kita tengok beberapa wajah globalisasi yang hadir saat ini.

\section{Masuknya Bahasa Asing sebagai Materi Pembelajaran}

Mata pelajaran Bahasa Inggris sudah menjadi mata pelajaran wajib di Indonesia, mulai dari pendidikan tingkat dasar sampai perguruan tinggi. Di Madrasah, mata pelajaran asing ini ditambah dengan Bahasa Arab. Beberapa lembaga pendidikan menengah memasukan Bahasa Mandarin, Jepang dan lain sebagainya. Kebijakan tersebut diyakini sebagai pintu masuk ke arah globalisasi karena ke depan peserta didik harus mampu bersaing secara global. Bahasa menjadi prasyarat mutlaknya. Sejak diberlakukan kurikulum 2013, Bahasa Inggris memang sudah tidak menjadi pelajaran wajib di tingkat SD, namun sebagian besar satuan pendidikan mempertahankan eksistensinya melalui kurikulum lokal. Di tingkat SMP, mata pelajaran Bahasa Inggris mendapatkan porsi jam pelajaran yang besar yaitu 4 JP, sementara di tingkat SMA hanya 2 JP. Di perguruan tinggi, Bahasa Inggris masih diakomodasi di Mata Kuliah Dasar Umum (MKDU).

Sebaliknya, Tabloid Diplomasi ${ }^{18}$ merilis beberapa Universitas luar negeri yang mengajarkan Bahasa Indonesia, yaitu Tokyo University of Foreign Studies, Jepang; University of Shouthern Queensland, Australia; Taras Shevchenko National University of

\footnotetext{
${ }^{15}$ Rusmin Tumanggor, Ilmu Sosial Dan Budaya Dasar. (Jakarta: Kencana Predana Media Group, 2010).

${ }^{16}$ Mahatma Gandhi, Towards New Education (Navajipan Publishing House, 1953).

${ }^{17}$ Ball, Education, Globalisation, and New Times, 65.

18 Tabloid Diplomasi, “No Title," last modified 2017, accessed September 21, 2021, http: / / www.tabloiddiplomasi.org/9-universitas-luar-negeri-dengan-mata-kuliah-bahasa-indonesia/ .
} 
Kyiv, Ukraina; Hankuk Univeristy of Foreign Studies, Korea Selatan; Hong Bang University, Vietnam; Universitas Mohammed V, Maroko; serta beberapa lembaga di Kanada, Hawaii dan Suriname.

\section{Hadirnya Jurusan Bahasa / Sastra Asing}

Selain sebagai sebuah mata pelajaran, pada skala yang lebih besar bahasa asing hadir sebagai sebuah jurusan atau kajian khusus, baik di perguruan tinggi kependidikan maupun perguruan tinggi umum. Di Tokyo University of Foreign Studies (TUFS) terdapat 26 bahasa asing yang diajarkan, salah satunya adalah bahasa Indonesia. Bahasa Indonesia sendiri termasuk dalam program studi Asia Tenggara, bersama dengan tujuh negara lainnya.

Selain di TUFS, ada pula universitas lain di Jepang yang membuka jurusan bahasa Indonesia, diantaranya Universitas Kajian Asing Tokyo, Universitas Tenri, Universitas Kajian Asing Osaka, Universitas Sango Kyoto, dan Universitas Setsunan. Kampus terbaik di Korea Selatan, Hankuk University of Foreign Studies (HUFS) bahkan membuka dua jurusan sekaligus, yaitu Department of Malay-Indonesia di College of Oriental Language serta Department of Malay-Indonesian Interpretation College of Interpretation and Translation.

\section{Kerjasama Program Antar Lembaga Pendidikan Lintas Negara}

Sebelum pandemi, muncul tren perguruan tinggi Indonesia mengadakan program Kuliah Kerja Nyata (KKN) atau Praktek Pengenalan Lapangan (PPL) lintas negara, program yang biasanya hanya dilakukan di lintas daerah saja, seperti yang dilakukan Universitas Muhammadiyah Jakarta yang mengadakan program KKN-nya di Malaysia, Universitas Darul Ulum Lamongan di Thailand, Universitas Hasanudin mengirim mahasiswa KKN-nya ke Malaysia dan Jepang ${ }^{19}$, Universitas Muhammadiyah Malang (UMM) melaksanakan Kuliah Kerja Nyata (KKN) Internasional di enam negara, yaitu Turki, Thailand, Malaysia, Cina, Kamboja dan Taiwan. Serta beberapa perguruan tinggi lainnya. Sebaliknya, Indonesia juga menerima program KKN mahasiswa luar negeri seperti yang terjadi di Propinsi DIY dan Jawa Tengah yang kedatangan 108 mahasiswa KKN reguler, 5 mahasiswa Double Degree asal Perancis, Jerman, Latvia, dan Norwegia, serta 8 mahasiswa dari Osaka City University.

Harian Republika ${ }^{20}$ mengabarkan bahwa di tingkat pendidikan dasar, pernah ada Program Kemitraan Sekolah Australia-Indonesia BRIDGE (Building Relationships through

19 IDNTimes, “Keren! 128 Mahasiswa Unhas KKN Ke Luar Negeri,” last modified 2019, https://sulsel.idntimes.com/news/sulsel/didit-haryadi/keren-128-mahasiswa-unhas-kkn-ke-luar-negeri/3.

${ }^{20}$ Republika, "Program Sekolah BRIDGE Bertemu Perwakilan Disdik Dan Kemenag," last modified 2021, https: / / www.republika.co.id/berita/qzgsm9423/program-sekolah-bridge-bertemu-perwakilan-disdik-dan- 
Intercultural Dialogue and Growing Engagement) yang merupakan gagasan AustraliaIndonesia Institute dan Asia Education Foundation (AEF). Program BRIDGE telah menjalin kerja sama dengan 189 sekolah Australia-Indonesia dan secara langsung melibatkan lebih dari 780 guru Australia dan Indonesia. Program ini dilaksanakan dalam rangka mendukung pembelajaran kolaboratif dan pedagogi melalui kemitraan sekolah internasional. Salah satu sekolah yang ikut program ini adalah Madrasah Ibtidaiyah Negeri 2 Tangerang Selatan.

\section{Kerjasama dengan Lembaga Donor Luar Negeri}

Salah satu lembaga yang konsern dengan dunia pendidikan Indonesia adalah USAID (United States Agency for International Development), mereka punya program diantaranya USAID Prioritas (Prioritizing Reform, Innovation, and Opportunities for Reaching Indonesia's Teachers) ${ }^{21}$ yaitu program dengan jangka waktu lima tahun dengan dana sekitar $\$ 83,7$ bekerja sama dengan guru, kepala sekolah, komite sekolah, dan siswa. Bersama pemerintah, program ini membantu pelaksanaan Kurikulum 2013 dengan menyediakan akses yang setara terhadap pendidikan yang berkualitas baik bagi siswa dan meningkatkan profesionalisme guru. Selain USAID, ada juga AUSAID (Australian AID) milik Australia.

\section{Asesmen Kompetensi Siswa tingkat Internasional}

Salah satu efek globalisasi pendidikan adalah adanya pengukuran atau penilaian kompetensi siswa di tingkat Internasional. Ada beberapa lembaga yang konsern dalam hal ini, diantaranya Organisation for Economic Co-operation and Development (OECD) yang melahirkan Program for International Student Assessment (PISA) dan International Association for Evaluation of Educational Achievement (IEA) yang melahirkan program Trends in International Mathematics and Science Study (TIMSS). Hasil dari PISA dan TIMSS yang begitu rendah dijadikan acuan pemerintah Indonesia untuk meningkatkan mutu pendidikan seperti lahirnya program Asesmen Nasional yang diantaranya berisi penguatan literasi dan numerasi. Literasi dan Numerasi sendiri adalah sebagian indikator asesmen PISA, disamping bidang sains.

kemenag\#: :text=Program BRIDGE menghubungkan sekolah dan,dengan sekolah-sekolah di Australia.\&text=Sejak 2008 hingga 2021\%2C program,kapasitas lebih dari 780 pendidik.

${ }^{21}$ USAID, "USAID Membawa Pendidikan Kelas Dunia Dengan Meningkatkan Profesionalisme Guru," last modified 2014, accessed February 1, 2022, https://www.usaid.gov/id/indonesia/press-releases/usaid-bringsworld-class-education-through-professional. 


\section{Pendirian Lembaga Pendidikan Lintas Negara}

CNN Indonesia ${ }^{22}$ merilis salah satu isu terkini terkait globalisasi pendidikan adalah didirikannya Universiti Muhammadiyah Malaysia (UMAM), perguruan tinggi Indonesia pertama yang berdiri di luar negeri dan diresmikan pada tanggal 5 Agustus 2021. Ada 5 program pendidikan doktoral yang disediakan, yaitu program pendidikan, program bisnis dan manajemen, program sosial, program Islam, dan program informasi teknologi. Di Indonesia, ada juga lembaga pendidikan milik asing, seperti Akadimiyah Al-Haramain Assuudiah, lembaga pendidikan milik pemerintah Arab yang menyediakan layanan pendidikan mulai jenjang TK sampai tingkat menengah. Selain di Indonesia, lembaga ini hadir pula di Malaysia dan Moskow.

\section{Pertukaran Dosen Lintas Negara}

Salah satu perguruan tinggi yang melakukan pertukaran dosen adalah Universitas Bengkulu (UNIB). Beberapa dosen UNIB mengikuti program pertukaran dosen internasional, diantaranya ke Thaksisn University Thailand, RMUTSV Thailand, UBB Cambodia, NFU China, TSU Thailand dan UMK Malaysia ${ }^{23}$. Ada juga program Fellowship (beasiswa) Short Course "Learning, action research, and outreach Making higher education boost food security” yang didukung dengan sponsor penuh (semua biaya kursus, perjalanan, akomodasi dan konsumsi) dari Orange Knowledge Program Pemerintah Belanda dan bantuan biaya pengurusan visa dari UNIB. Kegiatan tersebut diikuti 17 orang dari berbagai negara, yaitu Indonesia, Georgia, Mali, Benin, Nigeria, Ethiopia, Afrika Selatan, Ghana, Mesir,.Pakistan, Vietnam, Srilanka dan Mozambique.

\section{Pertukaran Pelajar antar Negara}

Dikutip dari laman indbeasiswa.com ${ }^{24}$, pemerintah Amerika Serikat, melalui Departemen Luar Negeri memberikan Beasiswa Penuh pertukaran pelajar SMA dengan nama perogram Kennedy-Lugar Youth Exchange and Study (YES), Program ini tahun 2003 dan telah memfasilitasi lebih dari 1000 siswa Indonesia ke Amerika Serikat. Program ini memberikan kesempatan kepada siswa/i yang aktif dan berprestasi, baik akademik maupun non-akademik dan berasal dari keluarga dengan keterbatasan ekonomi. Bagi siswa/i disabilitas (tuna netra, tuna rungu, tuna wicara, dan keterbatasan fisik). Selama

\footnotetext{
${ }^{22}$ cnnindonesia.com, "Muhammadiyah Bangun Kampus Pertama Indonesia Di Malaysia,” last modified 2021, https: / / www.cnnindonesia.com/nasional/20210812150724-20-679567/muhammadiyah-bangun-kampus-pertamaindonesia-di-malaysia.

${ }^{23}$ ksli.unib.ac.id, "Desiminasi Program Pertukaran Dosen Internasional UNIB Tahun 2015,” last modified 2015, http: / / ksli.unib.ac.id/desiminasi-program-pertukaran-dosen-internasional-unib-tahun-2015/.

${ }^{24}$ INDBeasiswa, "Pertukaran Pelajar SMA/Sederajat Ke Amerika Program KL YES Tahun 2022," last modified 2021, accessed February 1, 2022, https: / indbeasiswa.com/2021/08/pertukaran-pelajar-sma-kl-yes.html.
} 
masa program, peserta akan tinggal dengan keluarga yang ada di Amerika dan bersekolah di SMA setempat. Peserta akan mempelajari kehidupan di Amerika Serikat dan mendapatkan kesempatan untuk berinteraksi langsung dengan masyarakat sekitar melalui kegiatankegiatan yang dilaksanakan oleh Program YES yang akan menjadi pengalaman tak terlupakan. Selain itu, peserta juga berkesempatan untuk mengembangkan keterampilan pribadi dan kepemimpinan.

\section{PENUTUP}

Berdasarkan penelitian, ditemukan data bahwa globalisasi berimplikasi terhadap program pendidikan di beberapa lembaga pendidikan di Indonesia. Wajah dunia pendidikan mengalami tiga perubahan besar, yaitu pergeseran dari tradisi ke modernisasi, dari sosial spiritual ke komersial, dan dari berbasis lokal ke universal.

Peneliti mengidentifikasi ada delapan program sebagai bentuk globalisasi di dunia pendidikan, pertama masuknya bahasa asing sebagai materi pembelajaran, kedua hadirnya jurusan bahasa / sastra asing, ketiga kerjasama program antar lembaga pendidikan lintas negara, keempat kerjasama dengan lembaga donor luar negeri, kelima adanya Asesmen Kompetensi Siswa tingkat internasional, keenam pendirian lembaga pendidikan lintas negara, ketujuh pertukaran dosen lintas negara, dan kedelapan adanya pertukaran pelajar antar negara.

\section{DAFTAR PUSTAKA}

Ankarlina Pandu Primadata, Dwi Kasi Kusumawati. 2014. "Modernisasi Pendidikan Di Indonesia Sebuah Perspektif Sosiologis Terhadap Dunia Pendidikan Di Indonesia." Jurnal Analisa Sosiologi 3 No.1: 35.

Asmirawanti, Sulfasyah, Jamaluddin Arifin. 2016. "Komersialisasi Pendidikan.” Equilibrium Pendidikan Sosiologi IV No.2: 176.

Ball, Stephen J. 2007. Education, Globalisation, and New Times. New York: Routledge Taylor $\&$ Prancis Grou,

cnnindonesia.com. "Muhammadiyah Bangun Kampus Pertama Indonesia Di Malaysia." Last modified 2021. https://www.cnnindonesia.com/nasional/20210812150724-20679567/muhammadiyah-bangun-kampus-pertama-indonesia-di-malaysia.

Darmadi, H. 2011. Metode Penelitian Pendidikan. Bandung: CV. Alfabeta.

Darmaningtyas. 2004. Pendidikan Yang Memiskinkan. Yogyakarta: Galang Press.

Diplomasi, Tabloid. "No Title." Last modified 2017. Accessed September 21, 2021. http://www.tabloiddiplomasi.org/9-universitas-luar-negeri-dengan-mata-kuliah-bahasaindonesia/. 
Dzajifah, Nur. 2012. Proses Perubahan Sosial Di Masyarakat. Yogyakarta: Lembaga Penelitian dan Pengabdian kepada Masyarakat.

Gandhi, Mahatma. 1953. Towards New Education. Navajipan Publishing House.

Giddens, Anthony. 1991. The Consequences of Modernity. Cambridge: Polity Press.

IDNTimes. "Keren! 128 Mahasiswa Unhas KKN Ke Luar Negeri." Last modified 2019. https://sulsel.idntimes.com/news/sulsel/didit-haryadi/keren-128-mahasiswa-unhas-kknke-luar-negeri/3.

INDBeasiswa. "Pertukaran Pelajar SMA/Sederajat Ke Amerika Program KL YES Tahun 2022.” Last modified 2021. Accessed February 1, 2022. https://indbeasiswa.com/2021/08/pertukaran-pelajar-sma-kl-yes.html.

ksli.unib.ac.id. "Desiminasi Program Pertukaran Dosen Internasional UNIB Tahun 2015." Last modified 2015. http://ksli.unib.ac.id/desiminasi-program-pertukaran-doseninternasional-unib-tahun-2015/.

Martin Albrow, Elizabeth King (eds.). 1990. Globalization, Knowledge and Society. London: Sage.

Republika. "Program Sekolah BRIDGE Bertemu Perwakilan Disdik Dan Kemenag." Last modified 2021. https:/www.republika.co.id/berita/qzgsm9423/program-sekolah-bridgebertemu-perwakilan-disdik-dan-kemenag\#: - text=Program BRIDGE menghubungkan sekolah dan,dengan sekolah-sekolah di Australia.\&text=Sejak 2008 hingga 2021\%2C program,kapasitas lebih dari 780 pendidik.

Robertson, Roland. 1992. Globalization: Social Theory and Global Culture. London: Sage.

Scholte, Jan Aart. 2002. "Civil Society and Democracy in Global Governance." Global Governance 8 No. 3: 281-304.

Steger, Manfred. 2009. Globalization: A Very Short Introduction. New York: Oxford University Press.

Sugiyono. 2017. Metode Penelitian Kuantitatif, Kualitatif, Dan R\&D. Bandung: CV. Alfabeta. Suparman, Achmad. 2002. Ekonomi Lokal Dan Daya Saing Global. Jakarta: Bumi Aksara.

Tumanggor, Rusmin. 2010. Ilmu Sosial Dan Budaya Dasar. Jakarta: Kencana Predana Media Group.

USAID. "USAID Membawa Pendidikan Kelas Dunia Dengan Meningkatkan Profesionalisme Guru.” Last modified 2014. Accessed February 1, 2022. https://www.usaid.gov/id/indonesia/press-releases/usaid-brings-world-class-educationthrough-professional.

Zed, Mestika. 2008. Metode Penelitian Kepustakaan. Jakarta: Yayasan Obor Indonesia. 